\title{
The mammary glands of the tammar wallaby (Macropus eugenii) during pregnancy and lactation
}

\author{
Leigh Findlay
}

\begin{abstract}
School of Environmental and Life Sciences, Murdoch University, Murdoch, Western Australia 6150
\end{abstract}

\begin{abstract}
Summary. The 4 mammary glands of a nulliparous tammar wallaby differentiate during the 27-day pregnancy in preparation for lactation. Alveoli increase in size and number in the first half of gestation, and this increase continues slowly to term. At or soon after parturition the alveolar lumina enlarge as the gland to which the young is attached begins to secrete. The connective tissue stroma of the gland is progressively replaced throughout pregnancy and lactation with glandular tissue. Gross dimensions of the gland and alveolar size increase markedly in later lactation as the gland reaches maximum production. After parturition the other 3 glands simultaneously regress to a quiescent state until the next pregnancy. After weaning (Days 320-450 of lactation) the lactating gland involutes. This may occur concurrently with redifferentiation of the other glands for a new lactation. This pattern of differentiation is similar to that of the red kangaroo, and probably all macropodids.
\end{abstract}

\section{Introduction}

Lactation in macropodid marsupials differs in several interesting aspects from lactation in most eutherian mammals. Firstly, a preceding pregnancy is not necessary for the establishment of lactation in macropodids: the hormonal changes of the oestrous cycle are sufficient to prepare the glands for a normal lactation, which will ensue provided a sucking stimulus is applied to the gland at the correct stage of the cycle (Sharman \& Calaby, 1964). Also, the four mammary glands of a macropodid may differentiate independently. Two glands may be concurrently producing milks of differing compositions (Griffiths, McIntosh \& Leckie, 1972). A further difference between the patterns of macropodid and eutherian lactation is in the timing of events. In eutherians the mammary glands develop during pregnancy and lactation begins at, or soon after, birth. Maximum yields are reached early in the lactation cycle and the composition of post-colostrum milk does not change greatly within those species studied (Schmidt, 1971; Jenness, 1974). Macropodid neonates weigh $<1 \mathrm{~g}$ at birth, and although the lactation starts at or soon after parturition, maximum production is reached only after some months as the pouch young grows slowly. The composition of the milk also changes markedly, both qualitatively and quantitatively, during lactation (Messer \& Green, 1979; Green, Newgrain \& Merchant, 1980).

The tammar wallaby (Macropus eugenii) is a macropodid marsupial exhibiting both lactational and seasonal diapause (Tyndale-Biscoe, Hearn \& Renfree, 1974). Normally a single young is born and attaches to one of the 4 available teats in the pouch. Only the gland from which the young sucks continues to differentiate and produce milk. The remaining glands gradually regress and enter a quiescent phase. Tammar young are usually born from late January to mid-February, although births may occur until June. In the Murdoch University 
colony the gestation period is $26.9 \pm 0.56$ days (Young \& Renfree, 1979). Young permanently vacate the pouch at approximately Day 250 of lactation but are not fully weaned until Day 320-450 (Green et al., 1980).

The structure of the mammary glands of a marsupial has only been examined previously in any detail in one macropodid and one dasyurid species: the red kangaroo (Macropus rufus) (Griffiths et al., 1972) and the native cat (Dasyurus viverrinus) (O'Donoghue, 1912). The purpose of this study was to examine the structure of the mammary glands of the tammar wallaby at selected stages of pregnancy and lactation.

\section{Materials and Methods}

Animals and collection of samples. Animals were obtained from a breeding colony at Murdoch University (Western Australia) or as wild stock from Kangaroo Island (South Australia).

Stages of pregnancy were determined by removing the pouch young to reinitiate development of the quiescent blastocyst. The day of pouch young removal was designated Day 0 of pregnancy. Stages of lactation were determined from the head length of the pouch young using growth curves (Murphy \& Smith, 1970; W. E. Poole \& S. M. Carpenter, unpublished data). The day of birth was designated Day 1 of lactation.

Mammary glands at known stages of pregnancy or lactation were obtained either at necropsy or by surgical removal.

Mammary gland measurements. Using calipers, measurements of the two longest axes perpendicular to one another were taken on lactating mammary glands at known stages. These measurements were multiplied to produce a 'Mammary Size Index'. Although not an accurate measurement of the size of the gland, this index reflects changes in dimensions of the gland during lactation.

Histological techniques. Mammary glands were fixed intact in $4 \%$ neutral formal-saline. Representative pieces were embedded in paraffin wax, sectioned at $7 \mu \mathrm{m}$ thickness and stained with haematoxylin and eosin. Some sections were stained with Perl's Prussian Blue stain to detect ferric iron pigments.

Lactating and regressing glands were examined at Days 5, 10, 15, 20, 25 and 27 of pregnancy $(n=13)$, and at Days $1,2,5,7,16-30,40-60,60-100,130-180,190-270$ and $>300$ of lactation $(n=23)$, except at the later stages, when only lactating glands were studied. The glands of a juvenile female and an anoestrous adult female were also examined.

Representative sections were examined at $\times 100$ with an Olympus BHC light microscope fitted with a Weibel graticule. The point-counting technique described by Weibel (1963) was used to determine the percentages of the total volume of the gland occupied by alveolar cells, alveolar luminal space and connective tissue elements at the various stages of pregnancy and lactation. This is referred to as the volume density of the component. Five random representative fields per section were analysed with the 42-point Weibel test grid. The total number of 42 -point test grids per stage of pregnancy or lactation was 10,15 or 20.

The diameters of alveoli at the same stages of pregnancy and lactation were measured using an eyepiece graticule which had been calibrated with a stage micrometer. At each particular stage 35 alveoli were randomly selected and measured and the results averaged.

\section{Results}

In the absence of serial reconstructions or whole mounts, all tubular structures lined by a single layer of cells and bounded by only a basement membrane were termed alveoli. In developing glands, terminal ducts and alveolar ducts would also be included in this definition, but as these 
were indistinguishable from alveoli and are responsible for producing new alveoli by division, this was considered a useful working definition.

\section{Development}

The mammary glands of the juvenile female consisted of relatively few branching ducts embedded in a connective tissue stroma which was penetrated by strands of skeletal muscle. No alveoli were present (Pl. 3, Fig. 10).

The quiescent glands of an anoestrous female contained primary and secondary ducts, and rudimentary alveoli lined by a single layer of cuboidal epithelium. During pregnancy the glands developed in preparation for lactation. At Day 10 of pregnancy, a lobular pattern was evident. Clusters of alveoli surrounded a central bilaminar duct (Pl. 1, Fig. 1) and by Day 15 this structure was well defined. Most alveoli were small and roughly spherical with small lumina. The cells were cuboidal and their nuclei occupied a large proportion of their volume. Towards the end of pregnancy secretion was sometimes found accumulating in some of the lumina (Pl. 1, Fig. 2), suggesting an increase in activity of some cells. There appeared to be some reduction in the proportion of connective tissue stroma as the number of alveoli increased during pregnancy, but more dramatic histological changes were evident after parturition.

At, or soon after parturition, the lumina of the alveoli expanded as the gland began to secrete milk. The cells appeared to have increased cytoplasmic volume (Pl. 1, Fig. 3). However, much connective tissue stroma was still visible in the gland. The gland slowly increased in size and output as lactation progressed and the pouch young grew (Text-fig. 1).

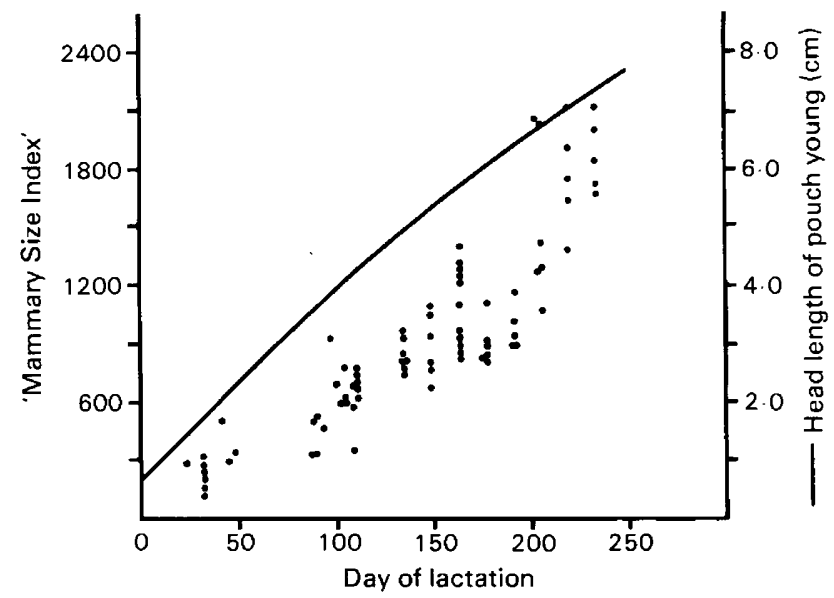

Text-fig. 1. A scatter diagram showing the 'Mammary Size Index' of lactating glands taken from animals with pouch young of $0-250$ days. The Index was obtained by multiplying measurements of the two longest axes of the gland perpendicular to one another. Also shown is a growth curve for pouch young using head length as a growth index (redrawn from the data of Murphy \& Smith, 1970).

The sucked teat showed a great increase in length during this period. At birth the teats measured 2-3 $\mathrm{mm}$ in length, whereas a teat used by a young tammar for 180 days measured approximately $23 \mathrm{~mm}$. The number of galactophores opening onto the teat end varied from 15 to 20 in the teats examined.

As the gland grew during lactation there was a progressive decrease in the proportional 
volume of stroma, and increases in the volume occupied by alveolar cells and their lumina (Text-fig. 2).

A gland at Day 57 consisted of lobules of small spherical alveoli surrounding a central duct (Pl. 2, Fig. 7). By about Day 100 the typical appearance of a fully lactating gland was reached: the alveoli were densely packed and many were distended with secretion. Some areas of the gland contained alveoli with empty lumina and high cuboidal epithelium. Others were so distended with secretion that their lining epithelium was flattened, and the cells were low cuboidal in appearance (Pl. 3, Fig. 9).

The average diameter of the alveoli measured increased gradually during pregnancy. As lactation began a further increase in diameter occurred, due, at least in part, to the opening of the lumina and their filling with secretion. In late lactation, when the output of the gland was maximal, the alveolar diameters were much increased (Text-fig. 2).

Mitotic figures were observed in most of the sections examined, but quantitative observations were not made. However, there appeared to be a low rate of division throughout early pregnancy with an increase in incidence of mitotic figures as birth approached. This increased frequency

\section{PLATE 1}

Fig. 1. Section of mammary gland at Day 10 of pregnancy. A bilaminar duct (d) surrounded by developing alveoli (arrowed) is visible. The alveoli have small lumina (l), and the cells have little cytoplasm.

Fig. 2. Section of mammary gland at Day 27 of pregnancy, showing portion of a duct (d), and alveoli (arrowed). The lumina of the alveoli (l) have expanded. Much connective tissue stroma (s) is still present.

Fig. 3. Section of lactating mammary gland at Day 2 of lactation. Cells of the alveoli (arrowed) have increased cytoplasmic volume and secretion (se) is evident in the alveolar lumina.

Fig. 4. Section of a non-sucked gland from the same animal as in Fig. 3. The appearance is similar to the sucked gland: the cells of the alveoli (arrowed) have increased cytoplasmic volume. Secretion (se) and some deciduous cells (c) are visible in the alveolar lumina.

\section{PLATE 2}

Fig. 5. Section of lactating gland at Day 7 of lactation. Alveoli (arrowed) are still separated by conspicuous connective tissue stroma (s). Secretion (se) is evident in some of the lumina.

Fig. 6. Section of a non-lactating gland from the same animal as in Fig. 5. The gland is beginning to regress and shows a loss of definition compared with the lactating gland. The alveolar cells (c) are undergoing autolysis.

Fig. 7. Section of a lactating gland at Day 57 of lactation, showing closely packed spherical alveoli (arrowed).

Fig. 8. Section of a non-lactating gland from the same animal as in Fig. 7. The gland has returned to a quiescent state with rudimentary alveoli (arrowed) embedded in connective tissue stroma (s).

\section{PLATE 3}

Fig. 9. Section of a lactating gland at Day 172 of lactation, showing alveoli with expanded lumina (1) and flattened epithelial cells (arrowed).

Fig. 10. Section of the mammary gland of a juvenile animal 230 days old. A few large bilaminar ducts (d) are seen embedded in connective tissue stroma (s). No alveoli are present.

Fig. 11. Section of mammary gland 60 days after cessation of lactation. Only a few small alveoli with collapsed lumina are visible (arrowed). The stroma (s) is hypercellular.

Fig. 12. Section of same gland shown in Fig. 11, stained with Perl's Prussian Blue. The iron-containing pigment (p) in the cytoplasm of macrophages stains black. Regressed alveoli are arrowed. 


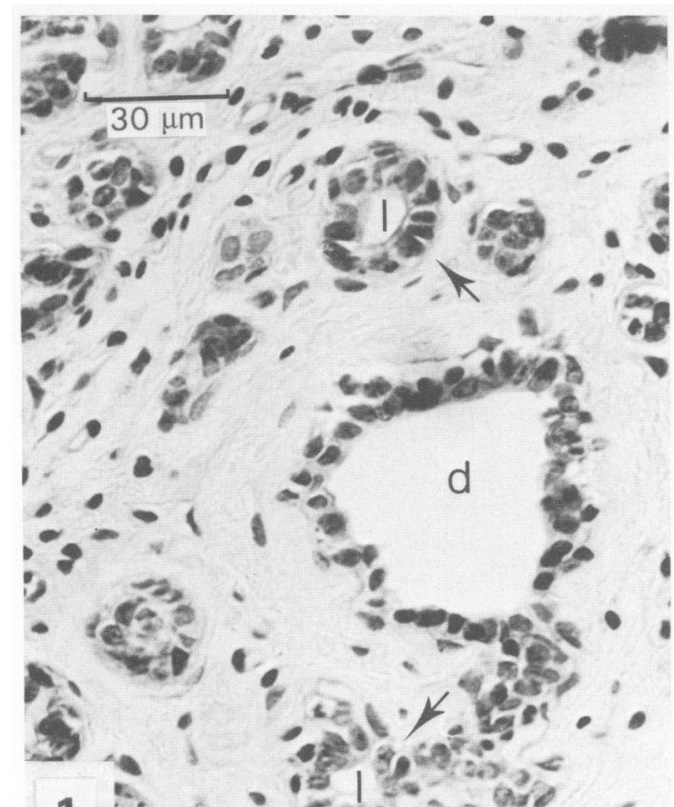

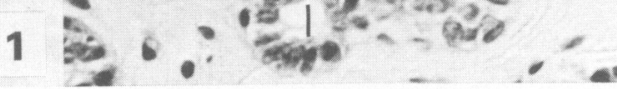

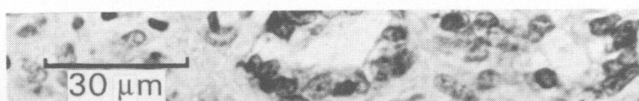

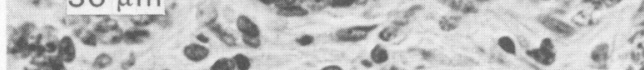

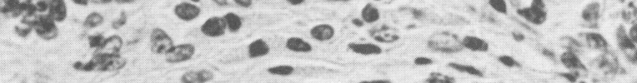

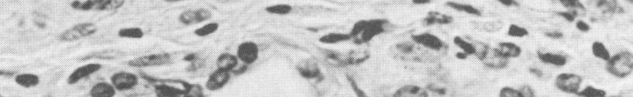

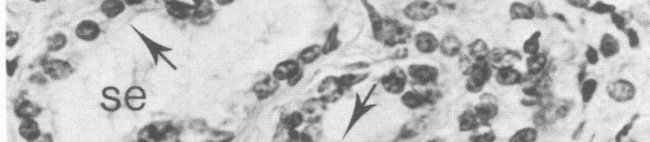

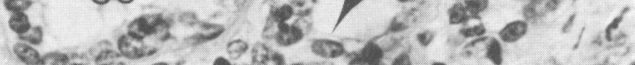

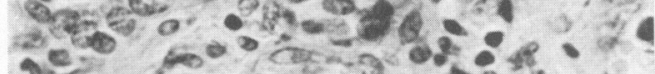
3.

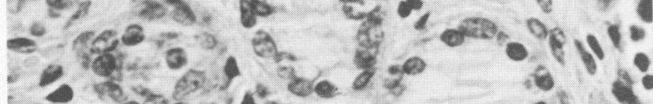

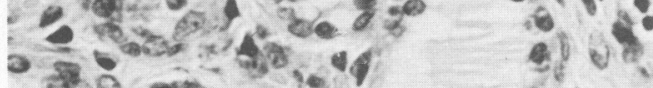

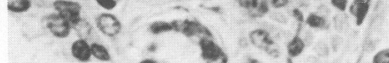
- $20 \cos ^{2} \mathrm{j}^{2}$

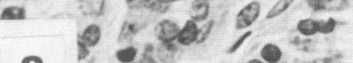

$3 \cdot 6 e^{-2}$

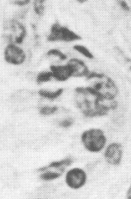

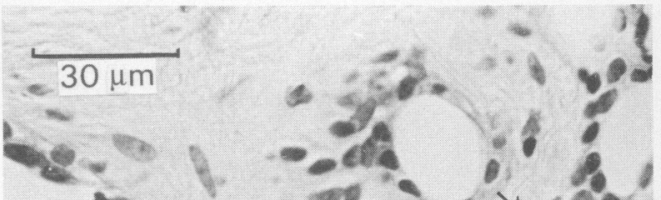

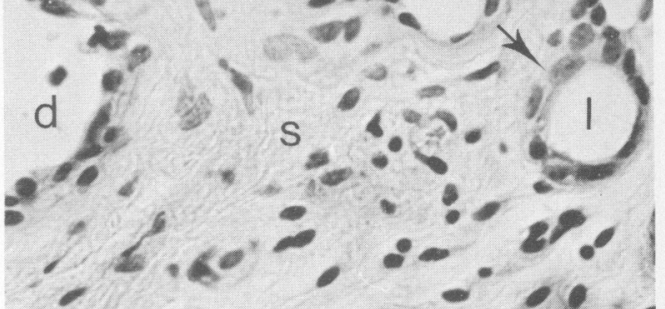

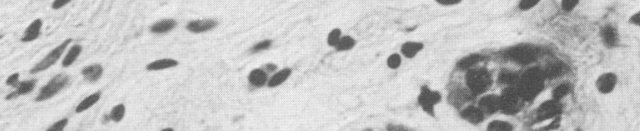

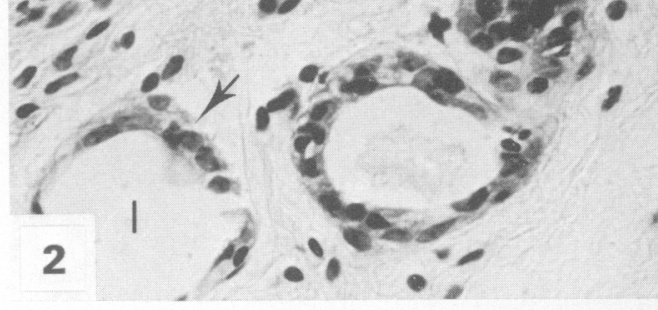

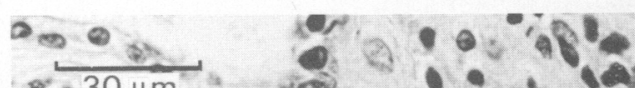

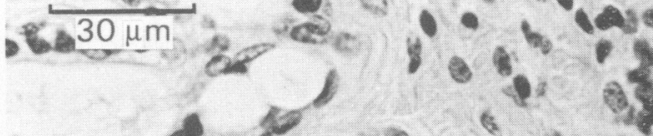

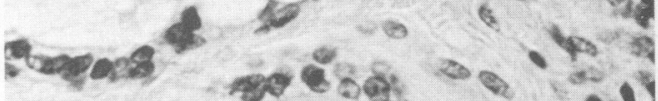
$\therefore$ de \%. a a 19 gias Q. 5 Q

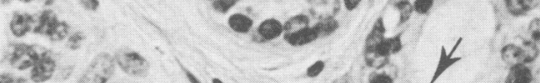
क\%

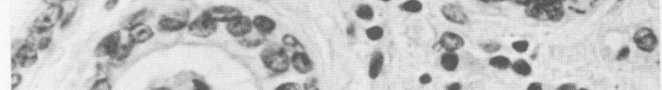
: 4 C

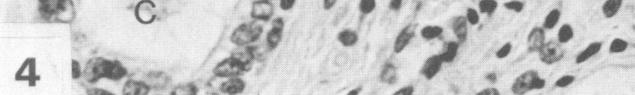

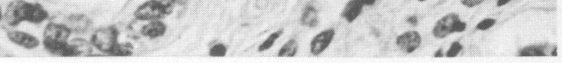

(Facing p. 62) 


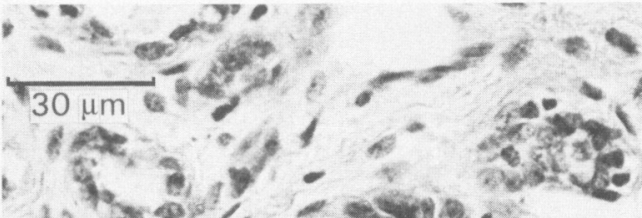

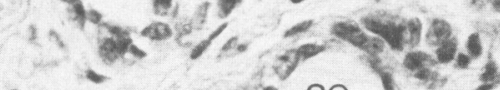

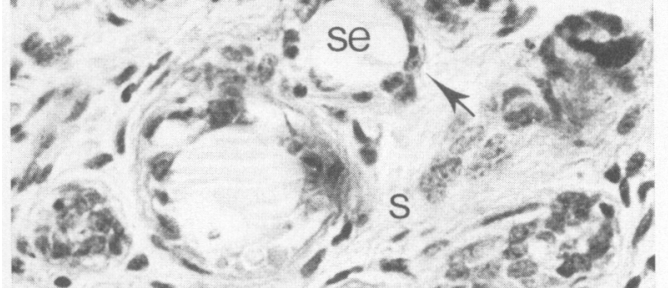
$\therefore 2-0+8 x=4$

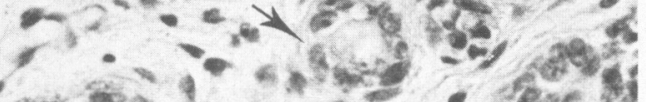

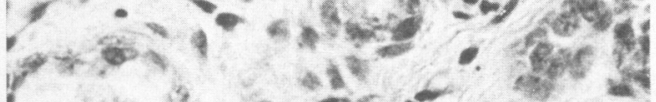
$-27,-\frac{1}{0}-5$

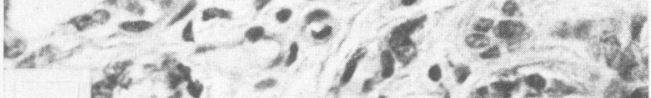

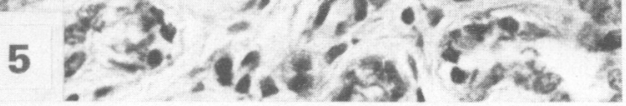

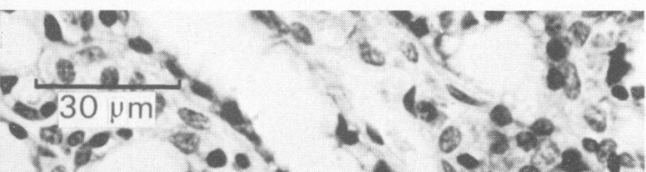

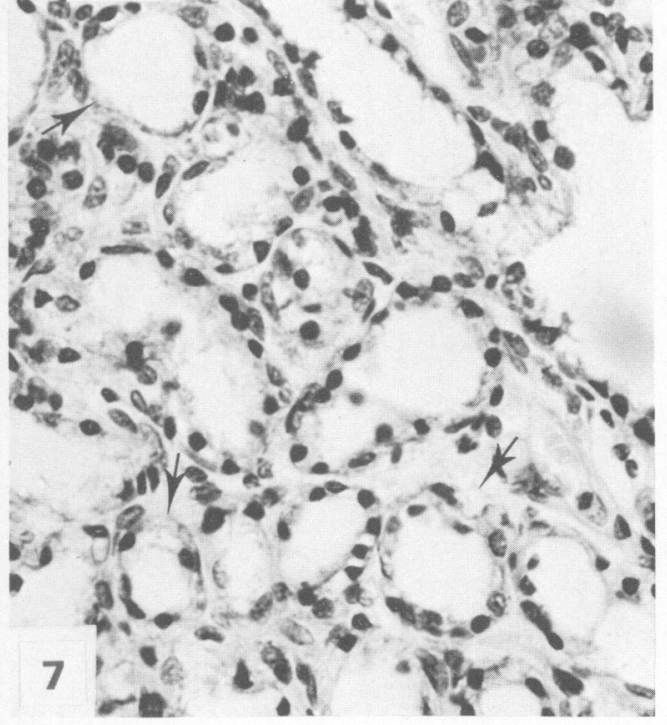

2, a-

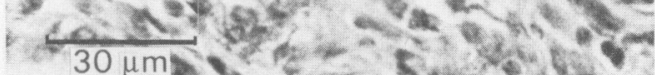

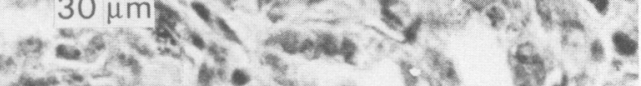

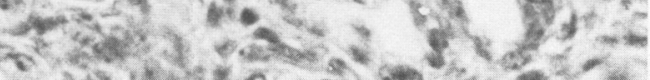

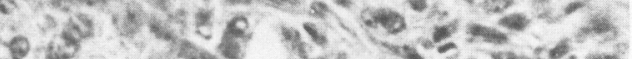

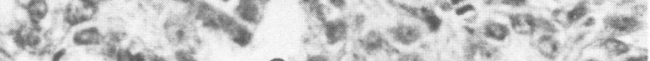

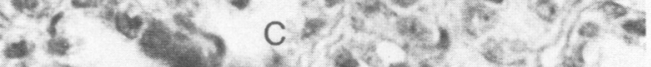

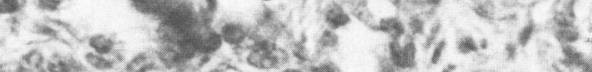

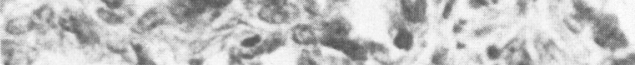

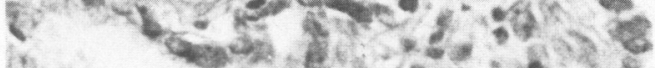

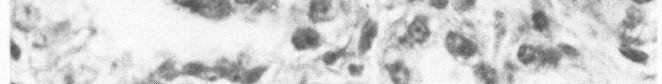

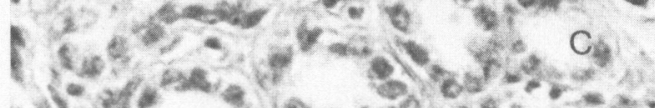

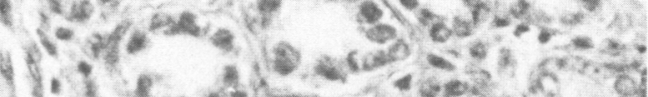

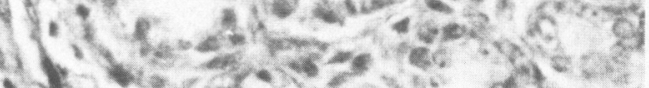

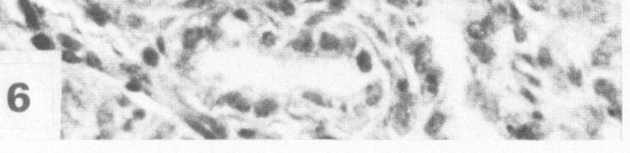

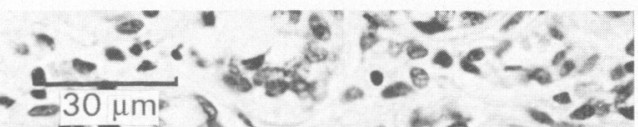
5.- 8

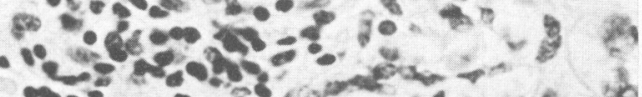
a

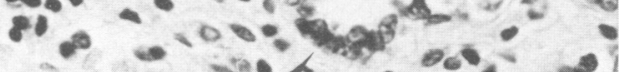

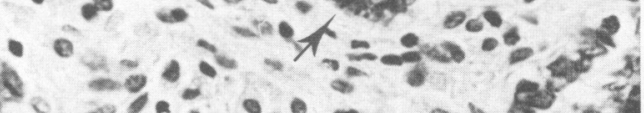

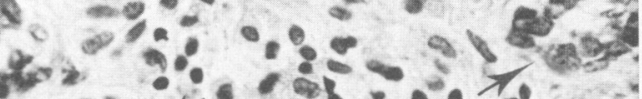

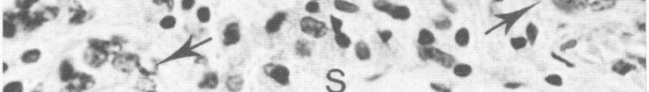

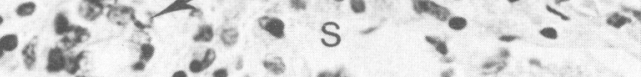
::

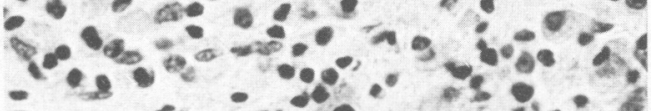

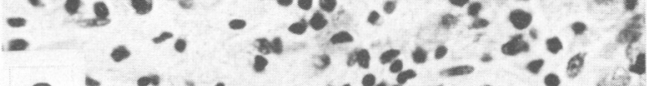
$8 \cdots+\cos c$ 
PLATE 3

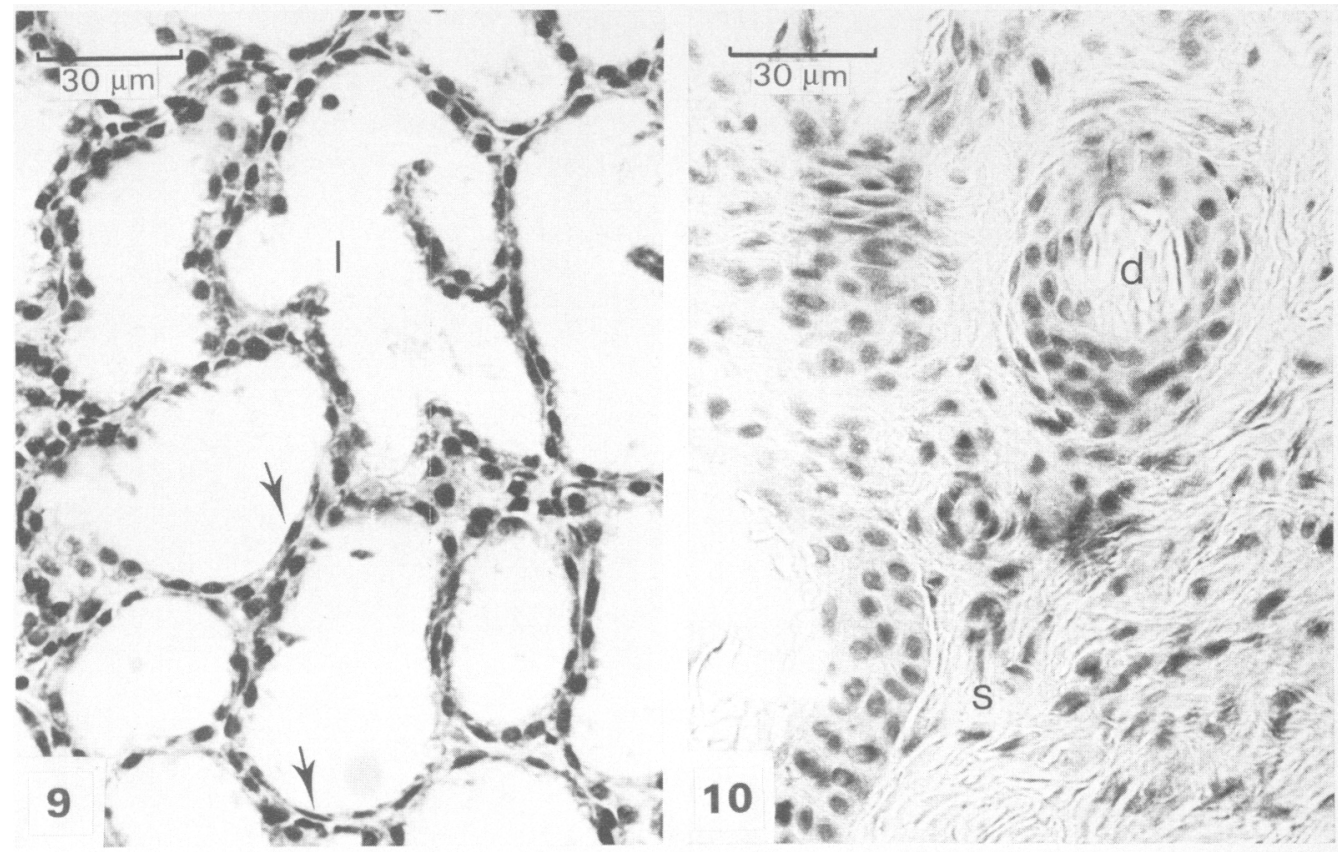

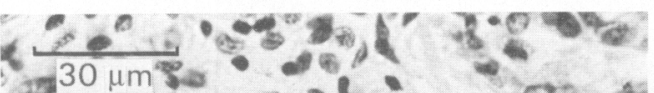

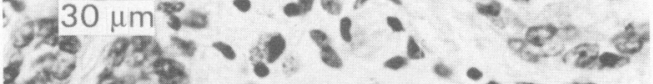

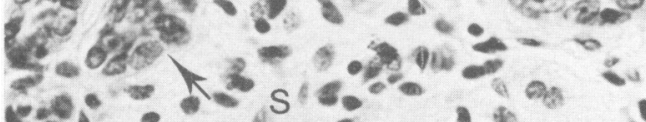

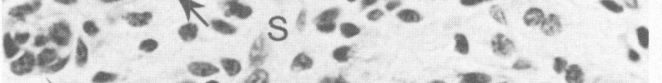
Ki

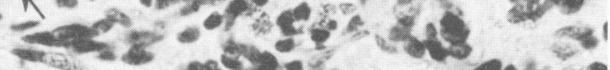
9 स.

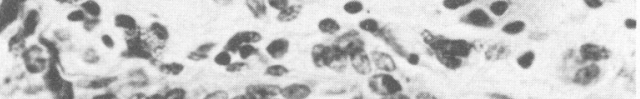

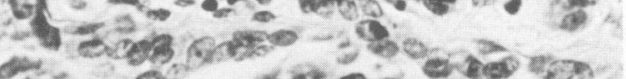

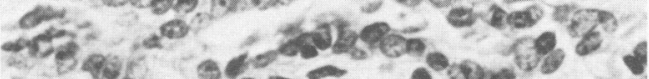

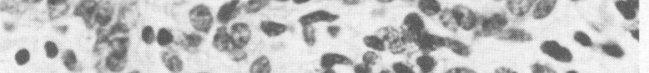

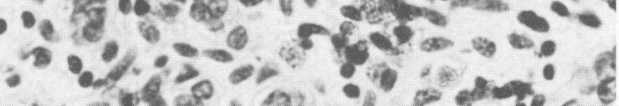

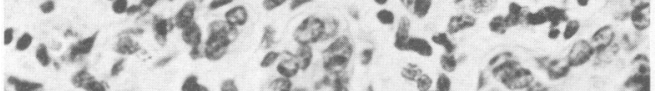

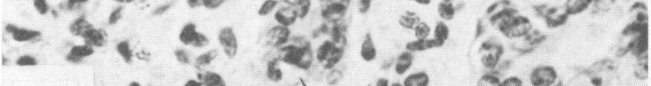

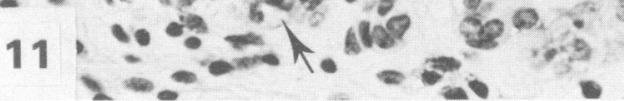

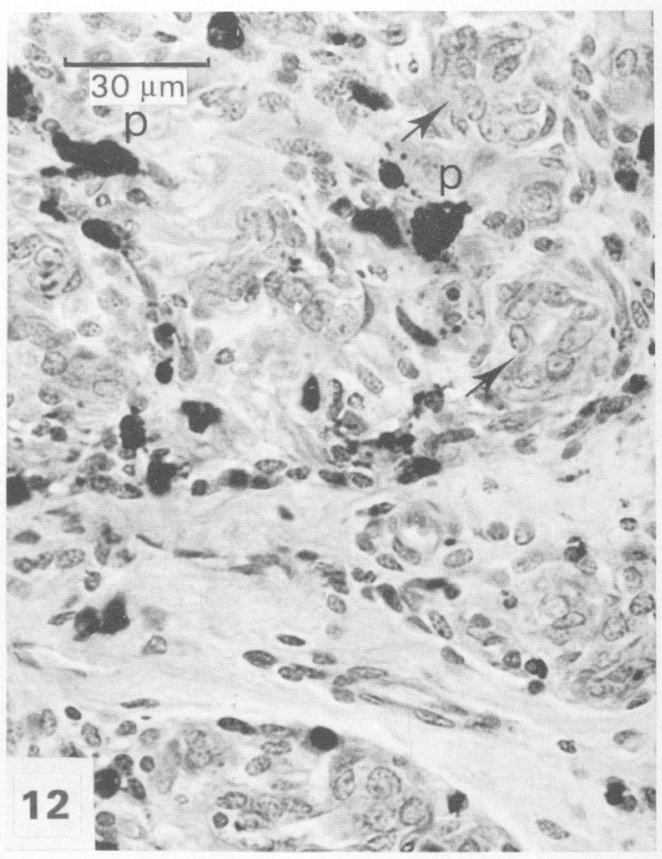




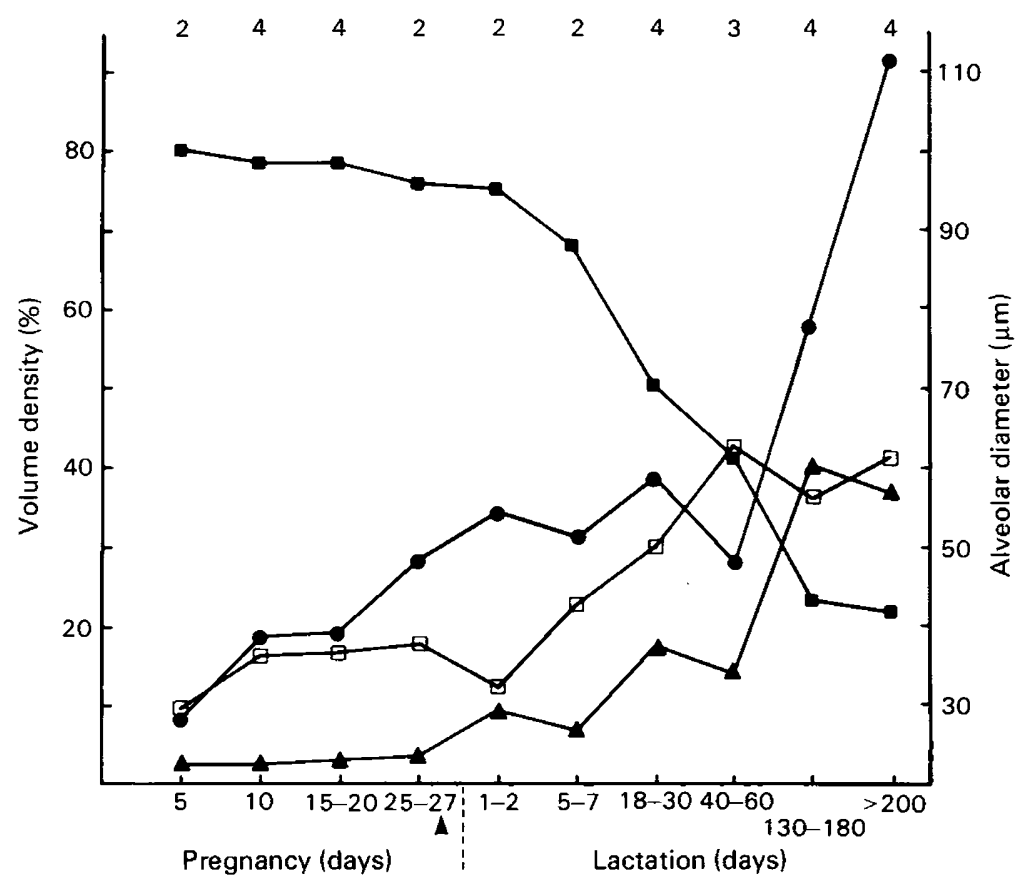

Text-fig. 2. The volume densities of alveolar cells $(\square)$, alveolar luminal space $(\boldsymbol{\Delta})$ and connective tissue stroma $(\square)$ in mammary glands during pregnancy and lactation. $\boldsymbol{\Delta}=$ parturition. The average alveolar diameters of 35 alveoli measured at the same stages are also shown ( $)$. The numbers of samples used to obtain the mean values shown are indicated.

appeared to be maintained for at least the first week of lactation. Mitotic figures were minimal in sections of glands from Day 40 of lactation onwards.

The changes described above occurred only in the lactating gland. If there had been no previous lactation, all 4 glands showed similar development throughout pregnancy. After birth and attachment of the young to a particular teat, the non-sucked glands underwent a gradual regression to a quiescent state. Until about Day 5 of lactation, the sucked and non-sucked glands had a similar appearance (Pl. 1, Fig. 4). Ducts and alveoli in both glands contained secretion and cells, although in the non-sucked glands the secretion accumulated and more cells were present. By Day 7, however, regressive changes were evident in the non-sucked glands: the lobular structure became less distinct and the gland appeared more homogeneous. Alveolar cells were tall cuboidal. Secretory material in the ducts and alveoli was reduced (P1. 2, Figs 5 and 6). This regression continued through early lactation. Differentiated alveolar cells were gradually reduced in number. In a specimen at $\mathbf{5 7}$ days the non-sucked glands had a quiescent appearance similar to that in the anoestrous adult (Pl. 2, Fig. 8).

\section{Involution}

After weaning or death of the young, the lactating gland regressed. The alveoli collapsed losing their spherical outline. Some of the alveolar cells were retained and persisted into the resting stage, but others underwent necrosis and were lost, presumably by lysis or expulsion from the alveolus (Hollman, 1974). The connective tissue appeared hypercellular, probably due to migration into the gland of cells which are involved in lysis, e.g. macrophages (Pl. 3, Fig. 11). In the regressing gland a brown pigment appeared which stained positively with Perl's Prussian 
Blue stain. The pigment appeared to be located within the cytoplasm of macrophages (Pl. 3, Fig. 12 ), and was presumably haemosiderin.

Involution eventually resulted in a gland with a large volume of stroma and a few small alveoli containing cells with reduced cytoplasmic volume.

\section{Discussion}

This study shows that the mammary glands of tammar wallabies differentiate during pregnancy in preparation for lactation. Secretory activity begins around the time of parturition. Similar development of the mammary glands has been reported in non-pregnant tammars (Ward, 1980). Secretory material was observed in the glands of a non-pregnant animal 27 days after removal of pouch young. These histological similarities are not surprising, since in the red kangaroo a preceding pregnancy is unnecessary for the establishment of lactation (Sharman \& Calaby, 1964). In most macropodids the entire gestation occurs within the length of one oestrous cycle (Tyndale-Biscoe et al., 1974). The luteal phase of the cycle is not prolonged by pregnancy, and plasma progesterone levels in pregnant and non-pregnant cyclic tammars are similar (Lemon, 1972). O'Donoghue (1912) also found a histological similarity between the mammary glands of pregnant and pseudopregnant native cats. In a few eutherians, such as the dog and the ferret, mammary development and sometimes milk production may follow a non-fertile cycle (Anderson, 1974; Forsyth \& Hayden, 1977; Short, 1977).

In the tammar and other macropodids, the non-sucked glands regress to a quiescent state while the single lactating gland continues to develop. The failure to remove milk products in the non-sucked glands is probably important in this regression, as it is in eutherians. The sucking stimulus (and concomitant release of lactogenic hormones) is unable to maintain lactation indefinitely without the removal of secretory products (Schmidt, 1971). In addition to the lactating and quiescent glands, in macropodids one mammary gland may be undergoing involution from the lactating condition. It is not known what period of time must elapse before the gland of the tammar is capable of redifferentiating and recommencing full lactation. Therefore, in a multiparous female, one of the glands may not be available to a neonate. Certainly neonates appear to avoid recently involuted glands.

The mechanisms which allow the 4 macropodid glands to differentiate independently are still unclear. Local effects on the glands induced by a sucking stimulus must be very important. Possibly hormone-receptor concentrations in the alveolar cells are altered by the presence and/or intensity of a sucking stimulus, making the cells more or less responsive to various hormonal stimuli. Prolactin receptor concentrations in the lactating gland of the tammar rise during pregnancy and continue to rise until about the 3rd month of lactation. Receptor concentrations in non-lactating glands decline rapidly after parturition (F. Stewart, personal communication). Sensitivity of the mammary gland to oxytocin appears to decline as lactation progresses in the agile wallaby (Macropus agilis) (Lincoln \& Renfree, 1981).

In eutherian species in which growth and cellular divisions in the mammary glands have been studied, it appears that mammary growth occurs during early to mid-pregnancy, with a final spurt of growth around the time of parturition or early lactation. A significant increase in mammary DNA content continues for up to 7 days into lactation in rats, mice and rabbits (Cowie, Forsyth \& Hart, 1980). O'Donoghue (1912) considered that increases in cell numbers in the mammary glands of the native cat were completed during the first half of pregnancy, and that subsequent increase in mammary size was due mainly to cell hypertrophy and mechanical increase resulting from alveolar luminal enlargement. Mitotic figures observed in the glands of tammar wallabies suggest that the alveolar cells may be increasing in number gradually throughout pregnancy. There seems to be an increase in the number of divisions during the perinatal period, continuing for at least 7 days into lactation. 
The small number of samples available for the morphometric study precluded rigorous statistical analysis. However, the morphometric data agree well with histological observations. The analyses suggest that, in the tammar, there is a period of growth during early pregnancy in which the alveoli increase in size and number. There is then little change until around the time of birth when the lumina of the alveoli begin to open. Throughout the course of pregnancy and lactation, the stroma is replaced progressively by alveolar tissue and the diameter of the alveoli increases.

It is not possible to state whether these changes are the result of continued alveolar cell divisions throughout lactation. Much of the increase in the various parameters is due to hypertrophy of the cells and distension of the alveoli with secretion, particularly in the later stages. The large increases in alveolar diameter occur after the time at which the young cease to be permanently attached to the teat (100 days). If this reflects a change in suckling patterns from continuous to intermittent, then alveolar distension may be related to the increase in suckling interval. However, the glands of macropodids may show an extended period of cellular division and growth in comparison with the glands of eutherians, because the former do not reach maximal production for some months after birth.

The pattern of mammary gland growth and development in the the tammar is similar to that of the red kangaroo (Griffiths et al., 1972), and is probably representative of all macropodids. The basic processes of mammary differentiation and growth are similar to those of eutherians. However, the timing of this differentiation and its relationship to the oestrous cycle, pregnancy and the post-partum period reflect the different reproductive strategies of these two groups.

I thank Dr M. Griffiths and Dr R. Cook for helpful discussions; Mr G. Shaw for assistance with the photographs; Mr G. Thompson for preparation of the Prussian Blue histology slides; $\mathrm{Dr}$ W. E. Poole and Dr S. M. Carpenter for permission to use unpublished growth curve data; Dr G. T. Meyer for guidance in morphometrical techniques; and Professor M. B. Renfree and Professor R. V. Short for helpful criticism.

This study was supported by grants from the National Institutes of Health (HD-09387), and the Commonwealth Scientific and Industrial Research Organisation to Professor M. B. Renfree. L.F. was supported by a Murdoch University Research Studentship.

\section{References}

Anderson, R.R. (1974) Endocrinological control. In Lactation, vol. 1, pp. 97-140. Eds B. L. Larson \& V. R. Smith. Academic Press, New York.

Cowie, A.T., Forsyth, I.A. \& Hart, I.C. (1980) Hormonal Control of Lactation, pp. 63-64. SpringerVerlag, Berlin.

Forsyth, I.A. \& Hayden, T.J. (1977) Comparative endocrinology of mammary growth and lactation. Symp. zool. Soc. Lond. 41, 135-163.

Green, B., Newgrain, K. \& Merchant, J. (1980) Changes in milk composition during lactation in the tammar wallaby (Macropus eugenii). Aust. J. biol. Sci. 33, 35-42.

Griffiths, M., McIntosh, D.L. \& Leckie, R.M.C. (1972) The mammary glands of the red kangaroo with observations on the fatty acid components of the milk triglycerides. J. Zool., Lond. 166, 265275.

Hollman, K.H. (1974) Cytology and fine structure of the mammary gland. In Lactation, Vol. 1, pp. 3-95. Eds B. L. Larson \& V. R. Smith. Academic Press, New York.
Jenness, R. (1974) The composition of milk. In Lactation, Vol. 3, pp. 3-107. Eds B. L. Larson \& V. R. Smith. Academic Press, New York.

Lemon, M. (1972) Peripheral plasma progesterone during pregnancy and the oestrous cycle in the tammar wallaby, Macropus eugenii. J. Endocr. 55, 63-71.

Lincoln, D.W. \& Renfree, M.B. (1981) Milk ejection in a marsupial, Macropus agilis. Nature, Lond. 289, 504-506.

Messer, M. \& Green, B. (1979) Milk carbohydrates of marsupials II. Quantitative and qualitative changes in milk carbohydrates during lactation in the tammar wallaby (Macropus eugenii). Aust. J. biol. Sci. 32, 519-531.

Murphy, C.R. \& Smith, J.R. (1970) Age determination of pouch young and juvenile Kangaroo Island wallabies. Trans. $R$. Soc. S. Aust. 94, 15-20.

O'Donoghue, C.H. (1912) The growth changes in the mammary apparatus of Dasyurus and the relation of the corpora lutea thereto. $Q$. $J l$ microsc. Sci. 57, 187-234. 
Schmidt, G.H. (1971) Biology of Lactation. W. H. Freeman, San Francisco.

Sharman, G.B. Calaby, J.H. (1964) Reproductive behaviour in the red kangaroo, Megaleia rufa, in captivity. CSIRO Wildl. Res. 9, 58-85.

Short, R.V. (1977) The aetiology of mammary cancer in man and animals. Symp. zool. Soc. Lond. 41, 211-230.

Tyndale-Biscoe, C.H., Hearn, J.P. \& Renfree, M.B. (1974) Control of reproduction in macropodid marsupials. J. Endocr. 63, 589-614.
Ward, K.L. (1980) The role of progesterone in parturition and lactogenesis in the tammar wallaby (Macropus eugenii). Honours thesis, Murdoch University, Western Australia.

Weibel, E.R. (1963) Morphometry of the Human Lung. Springer-Verlag, Berlin.

Young, I.R. \& Renfree, M.B. (1979) The effects of corpus luteum removal during gestation on parturition in the tammar wallaby (Macropus eugenii). J. Reprod. Fert. 56, 249-254.

Received 11 June 1981 